\title{
1 Population structure of the oviparous South-West European Common lizard
}

2 Jose Luis Horreo. ${ }^{12, *}$, María Luisa PeláeZ ${ }^{23}$, Merel C. Breedveld ${ }^{124}$, Teresa Suárez ${ }^{3}$, María

3 Urieta $^{2}$, Patrick S. Fitze ${ }^{1.2}$

4 Department of Ecology and Evolution (DEE), University of Lausanne, 1015 Lausanne,

5 Switzerland.

6 Department of Biodiversity and Evolutionary Biology, Museo Nacional de Ciencias

7 Naturales (MNCN-CSIC), José Gutiérrez Abascal 2, 28006 Madrid, Spain.

$8 \quad{ }^{3}$ Department of Cellular and Molecular Physiopathology, Centro de Investigaciones

9 Biologicas (CSIC), Calle Ramiro de Maetzu 9, 28040 Madrid, Spain.

$10{ }^{4}$ Animal Ecology, University of Potsdam, Maulbeerallee 1, 14469 Potsdam, Germany

12 *Corresponding author: +34 9141113 28, ext. 981355; horreojose@ gmail.com

14 Abstract

15 Gene flow is an important factor determining the evolution of a species, since it directly

16 affects population structure and species' adaptation. Here we investigated population

17 structure, population history, and migration among populations covering the entire

18 distribution of the geographically isolated South-West European common lizard

19 (Zootoca vivipara louislantzi) using 34 newly developed polymorphic microsatellite markers. The analyses unravelled the presence of isolation by distance, inbreeding,

21 recent bottlenecks, genetic differentiation, and low levels of migration among most

22 populations, suggesting that Zootoca vivipara louislantzi is threatened. The results point

23 to discontinuous populations and are in line with physical barriers hindering

24 longitudinal migration South to the Central Pyrenean cordillera and latitudinal 
25 migration in the central Pyrenees. In contrast, evidence for longitudinal migration exists

26 from the lowlands north to the central Pyrenean cordillera and the Cantabrian

27 mountains. The location of the populations South to the Central Pyrenean cordillera

28 were identified as the first to be affected by global warming, thus management actions

29 aimed at avoiding population declines should start in this area.

30

31 Keywords climate change; conservation; first-generation migrant, gene flow; IBD;

32 Zootoca vivipara.

\section{Acknowledgements}

35 J. L. H. was supported by both a EU Marie Curie-Clarín CoFund grant (ACA14-26) and 36 the Spanish Ministry of Economy and Competitiveness postdoc grants FPDI-2013-

3716116 and IJCI-2015-23618. Project funds were provided by the Swiss National 38 Science Foundation (PPOOP3_128375, PP00P3_152929/1 to P.S.F.) and the Spanish

39 Ministry of Education and Science (CGL2008-01522, CGL2012-32459, CGL2016-

4076918 to P.S.F.). The authors do not have any competing interests. 


\section{Introduction}

Gene flow is among the most important determinants of population structure, population persistence, and local adaptation (Garant et al. 2007). Gene flow reflects the transfer of genetic information from one population to another one, and is related to the number of migrants among populations. Several factors have been proposed to affect migration rate. Among the most prominent ones are physical barriers (e.g. rivers, mountains, deserts), climatic barriers (i.e., unsuitable climatic conditions hindering migration), and behavioural barriers (e.g. sexual selection; Geffen et al. 2004; Tobler et al. 2009). Moreover, the presence and permeability of such barriers can vary during the evolutionary history of a species (Coulon et al. 2004; Sharma et al. 2013). Connectivity among populations is suggested to be affected by climate change (Mieszkowska et al., 2007; Horreo et al., 2011; Anderson et al., 2009; Munday et al. 2009 Coral Reefs) and recent results suggest that on the northern hemisphere climatic change may first affect populations at the southern range limit (Horreo et al., 2014). Consequently, information about population structure, population history, and gene flow among populations is essential in order to understand past, current, and future population dynamics, as well as whether populations might be affected by climatic change.

Here we investigate migration, inbreeding, and bottlenecks in the European common lizard Zootoca vivipara to infer past and recent dynamics and to provide a base for future studies. More specifically, we estimated migration in Z. vivipara louislantzi, a subspecies inhabiting the southern limit of its wide geographic distribution (Horreo et al. 2018; Surget-Groba et al. 2006), and thus the geographic area where climate change is suggested to first affect populations (Horreo et al., 2014).

Zootoca vivipara is a model species for the study of evolution, populations dynamics, behaviour, coloration, and ecology of dispersal (Aragon and Fitze 2014; Bestion et al. 
2015; Cote et al. 2007; Cornetti et al. 2015; Cotto et al. 2015; Fitze et al. 2010; Fitze and Le Galliard 2008; Horváthová et al. 2013; Le Galliard et al. 2005; Peñalver-Alcázar et al. 2016; Recknagel et al. 2018; San-Jose et al. 2014; Sinervo et al. 2010; SurgetGroba et al. 2006). It exhibits two oviparous (clade A and B) and four viviparous clades (clades: C, D, E, and F; Horreo et al. 2018). The oviparous South-West European common lizard, Z vivipara louislantzi (clade B; Surget-Groba et al. 2006), inhabits south-western Europe (northern Spain and south-western France), and its geographic distribution does not overlap with the geographic distribution of the other clades (Horreo et al. 2018; Surget-Groba et al. 2006). Fine-scale analyses revealed that Z.v. louislantzi consists of four major subclades: B1, the NW Spain (Galicia and Cantabrian Mountains); B2, the southern France (northern slopes of the Pyrenees; Mila et al. 2013); B3, the North-Central (NC) Spain (Basque country); and B4, the NE Spain (southern slopes of the Pyrenees) subclade (Horreo et al. 2018; Mila et al. 2013). Despite the large research interest (see above), only two studies investigated gene flow and migration in Z. vivipara (Mila et al. 2013; Cornetti et al 2015). Milá et al. (2013) concluded that mountain ranges act as drivers of isolation and differentiation in Z. v. louislantzi, and Cornetti et al. (2015) found no introgression between clade A and E in the Alps (Z.v. vivipara and Z.v.carniolica) despite the absence of physical barriers. Here we sampled a larger number of individuals and used specific newly developed nuclear markers (Horreo et al. 2018) to provide the first direct estimates of gene flow in Z. v. louislantzi.

89

\section{Material and Methods}

$91 \quad$ Study Area 
92 Samples from ten different lizard populations (20 samples/population) covering the

93 distribution of Z.v. louislantzi were collected (Fig. 1). These populations belong to four

94 different oviparous subclades (Mila et al. 2013). All sampled populations were located

95 in northern Spain and southern France (Fig. 1): Xistral and Andara (subclade B1;

96 Western Cantabrian Mountains); Pinet, Louvie, and Aubisque (subclade B2; northern

97 slopes of the Pyrenees); Estacas and Barazar (subclade B3: Eastern Cantabrian

98 Mountains and Basque country); and Culivillas, Zuriza and Beret (subclade B4;

99 southern slopes of the Pyrenees), following AFLP-inference by Mila et al. (2013). Non-

100 invasive tissue sampling was conducted in 2014 and 2015 under licence of different

101 institutions (Instituto Aragonés de Gestión Ambiental LCE/Mp 24/2012/426 and

102 500201/24/2013/12572; Service Nature Languedoc-Roussillon arrêté № 2014304-004;

103 DREAL Aquitaine; Parc National des Pyrénées 2012-55 \& 2016_8; Xunta de Galicia

104 071/2014; Generalitat de Catalunya; Asturias; Parque Nacional Picos de Europa;

105 Bizkaiko Foru Aldundia $\mathrm{Zk} / \mathrm{N}^{\circ}$ 1079). All sampling was performed in accordance with

106 relevant guidelines and regulations.

107 The airline distances among sampled populations were highly variable, from less

108 than $20 \mathrm{~km}$ between Louvie and Aubisque, to more than $800 \mathrm{~km}$ from Xistral to Pinet.

109 Specimens were mainly adults (only 6 juveniles were included), and the sex ratio was

110 balanced (97 males and 103 females in total).

111 DNA analyses

112 After DNA extraction from skin and tail tips (for methodological details see Horreo and

113 Fitze 2015), 34 newly developed microsatellite loci were amplified in all specimens

114 following the original protocol (seven multiplexes; Horreo et al. 2017).

115 MICROCHECKER (Van Oosterhout et al. 2004) was employed to check for the

116 presence of null alleles and large allelic dropout. All loci were checked for linkage 
117 disequilibrium (LD) using GENEPOP online (http://genepop.curtin.edu.au). The

118 average number of alleles (Na) as well as the observed (Ho) and expected

119 heterozygosity (He), were estimated with GENETIX (Belkhir et al. 2004). Departures

120 from Hardy Weinberg Equilibrium (HWE), heterozygote deficiency $\left(\mathrm{F}_{\text {Is }}\right)$, and the

121 fixation index $\left(\mathrm{F}_{\mathrm{sr}}\right)$, were calculated using GENODIVE (Merimans and Van Tienderen

122 2004). Test significance was determined using sequential Bonferroni adjustments (Rice

123 1989), which accounts for multiple testing. Differences among subclades in the number

124 of alleles per locus as well as in observed and expected heterozygosity were tested by

125 analysis of variance (ANOVA) employing JMP 11.2.0 software.

126 To analyse the population structure, the program STRUCTURE v.2.3.4 (Falush

127 et al. 2007) was employed using the Bayesian assignment probability test. A model of

128 no admixture with the Locprior option and correlated allele frequencies was used to

129 assign individuals to a given number of genetic clusters $(K)$. Ten different repetitions of

130 one million steps were run for each number of $K$ (from 2 to 10 ; note that genetic

131 information from 10 populations was analysed) after a $10 \%$ burn-in. The optimal $K$ was

132 assessed with Structure selector (http://lmme.qdio.ac.cn/StructureSelector), a web based

133 software to select and visualize the optimal number of genetic clusters (Li \& Liu 2018),

134 using the methods by Puechmaille (2016) and Evanno et al. (2005).

135 The number of migrants per generation $(\mathrm{Nm})$ among populations (using the

136 private alleles method), and the presence of isolation by distance (IBD) were calculated

137 with GENEPOP online (link above). To test for recent gene flow, first-generation

138 migrants were determined with GeneClass v.2.0 (Piry et al. 2004) using the following

139 settings: L_max/L_home likelihood computation, a Bayesian criteria of computation

140 (Rannala \& Mountain 1997), and Monte Carlo resampling (Paetkau et al. 2004) with

14110,000 simulated individuals and 0.05 of type I error (alpha). 

drastic reductions in population sizes) was tested with Bottleneck v.1.2.02 using settings

144 for microsatellite data (Piry et al. 1999): the two phase model (TPM settings: variance

145 for TPM $=30$, proportion of SMM in TPM = 70\%) and the 2-tailed Wilcoxon sign-rank

146 test with 10,000 interactions. In these analyses, significant $P$-values point to the

147 presence of recent bottlenecks. To detect older bottlenecks, the Garza-Williamson index 148 (2001) was estimated using Arlequin v.3.11 (Excoffier and Lischer 2010). Garza and 149 Williamson's (2001) method estimates $\mathrm{M}(\mathrm{M}=\mathrm{k} / \mathrm{r}$ being $\mathrm{k}$ the number of alleles and $\mathrm{r}$ 150 the allelic range) and $\mathrm{M}<0.68$ corresponds to past bottlenecks and $\mathrm{M}>0.80$ allows to 151 conclude that no past bottlenecks existed.

\section{Results}

154 The 34 microsatellite loci successfully amplified $92.9 \%$ of the genotypes and the 155 genetic diversity within populations was high (Table 1). MICROCHECKER detected 156 the presence of null alleles in three of the 34 microsatellite loci (ZV17, ZV25 and 157 ZV33) and another three loci were not in HWE in the majority of the populations (ZV11,ZV12,ZV13 and ZV17; Table 1). These loci were thus discarded from subsequent analyses, and the final dataset included 28 microsatellite loci. The average

160 Na measured over all populations was 20.86 alleles per locus with the least variable 161 locus (ZV33) comprising 12 different alleles and the most variable one (ZV34)

162 comprising 37 alleles. The average Na per population ranged between 7.36 and 12.07, 163 Ho ranged between 0.60 and 0.70 , and He between 0.60 and 0.82 .

164 No significant differences among subclades (B1, B2, B3, B4) existed in the 165 number of alleles per locus $\left(\mathrm{Na}\right.$; ANOVA: $\left.\mathrm{F}_{3,6}=3.855, P=0.075\right)$ and the observed 166 heterozygosity (Ho; ANOVA: $\left.\mathrm{F}_{3,}=4.529, P=0.055\right)$. Significant differences existed in 
167 the expected heterozygosity (He; ANOVA: $\left.\mathrm{F}_{36}=6.445, P=0.026\right)$. The Tukey's HSD

168 test showed that He was significantly lower in subclade B1 compared to subclades B2 169 and B3.

$170 \quad F_{\text {Is }}$ ranged from -0.004 to 0.146 , being positive and significant in all populations

171 except in Xistral, where it was negative and not significant (Table 2). In seven

172 populations, Wilcoxon tests unravelled a recent reduction of effective population size

173 (Wilcoxon test: $P<0.05$; Table 2) and Garza-Williamson indices unravelled no

174 evidence for past reductions (G-W: $\mathrm{M}>0.80$; Table 2), while in three populations:

175 Culivillas, Barazar, and Beret, no evidence for recent (Wilcoxon test: $P>0.05$ ) and past

176 reductions $(\mathrm{G}-\mathrm{W}: \mathrm{M}>0.80$; Table 2$)$ existed.

$177 \quad \mathrm{~F}_{\mathrm{sr}}$ analyses showed genetic differentiation $(P$-value $<0.01)$ among all

178 population pairs with the exception of Louvie and Aubisque (Table 3), both belonging

179 to subclade B2 from southern France. Both, Puechmaille's (2016) and Evanno et al.'s

180 (2005) methods showed that $K=7$ was the optimal number of clusters for the

181 STRUCTURE analyses (Fig. 2). The structure analyses attributed most of the

182 populations to different clusters (Xistral, Andará, Culivillas, Pinet, Beret). Estacas and

183 Barazar were assigned to same genetic unit and also Louvie, Aubisque, and partly

184 Zuriza.

185 The number of migrants $(\mathrm{Nm})$ between populations was low, in general less than

186 one migrant per generation (Table 3 , Fig. 1 ). $N$ m values above 1 existed among the

187 following population pairs: Louvie and Barazar, Pinet, Beret, or Zuriza, and Aubisque

188 and Zuriza. $N m$ values were highest $(N \mathrm{~m}>2)$ among Barazar and Estacas (both

189 belonging to subclade B3) and Louvie and Aubisque (both belonging to subclade B2).

190 Low migration existed between populations whose airline distance crosses mountains

191 (e.g. from Culivillas to Beret $N \mathrm{~m}=0.3$, Barazar $N \mathrm{~m}=0.4$, Estacas: $N \mathrm{~m}=0.4$, or Zuriza 
$192 N \mathrm{~m}=0.7$; or from Andara to Xistral $N \mathrm{~m}=0.4$, Estacas $N \mathrm{~m}=0.6$, or Barazar $N \mathrm{~m}=0.5)$.

193 Isolation By Distance (IBD) analyses over the entire distribution (maximal distance 800

$194 \mathrm{~km})$ were statistically significant $\left(\mathrm{F}_{1,3}=20.961, P<0.01, \mathrm{R}^{2}=0.328\right)$, and IBD was also

195 present within populations located close to the Pyrenees (maximal distance $460 \mathrm{~km}$ :

196 subclades B2, B3, B4; $\left.\mathrm{F}_{1,26}=5.026, P=0.034, \mathrm{R}^{2}=0.162\right)$. A total of fifteen first-

197 generation migrants ( $7.5 \%$ of the total individuals) were detected within the sampled

198 individuals: one in Zuriza (coming from Louvie), six in Louvie (all of them coming

199 from Aubisque), another six in Aubisque (all of them from Louvie), and two in Estacas

200 (one coming from Barazar and the other one from Andara).

202 Discussion

203 Knowledge about gene flow and migration provides valuable insight into the process of

204 lineage divergence and the past history; and it is essential for conservation. Here we

205 investigated migration among populations covering the geographic distribution of the

206 South-West European common lizard Zootoca vivipara louislantzi (clade B of $Z$.

207 vivipara, Horreo et al. 2018). The results provide evidence for strong genetic

208 differentiation (Table 3), with most populations belonging to a different genetic unit

209 (Figs. 1, 2). Two genetic units included several populations, and among those the

210 number of migrants per generation was estimated to be higher than two (Figs. 1, 2).

211 Significant heterozygote deficiency, which points to inbreeding, was present in $90 \%$ of

212 the studied populations and evidence for recent bottlenecks existed in the $70 \%$ of the

213 populations (significant Wilcoxon tests, Table 2), while no evidence existed for past

214 bottlenecks in any of the populations (all Garza-Williamson indices: $M>0.84$; Table 2 ).

215 The presence of significant Wilcoxon tests and the absence of past bottlenecks suggest

216 that effects on effective population sizes are caused by recent factors (e.g. the current 
217 climatic change) that negatively affect Z. v. louislantzi's populations. Moreover, the

218 strong genetic differentiation and population structure, the omnipresence of inbreeding,

219 and the generally low migration rates detected in Z. v. louislantzi, point to the existence

220 of isolated populations. In line with that was the genetic distance, which increased with

221 geographic distance over the entire distribution of Z. v. louislantzi (Fig. 3), and also

222 over shorter distances, i.e. within populations located close to the Pyrenees.

The number of migrants per generation $(\mathrm{Nm})$ between Louvie and Aubisque,

both populations belonging to subclade B2 (S France), was highest ( $>2$ migrants per

generation). Given that $\mathrm{Nm}$ reflects the proportion of genetic exchange existing among

two populations, but not necessarily the number of individuals that migrate from one population to the other population (Slatkin 1985), we also quantified the number of first-generation migrants. Twelve first-generation migrants were detected between Louvie and Aubisque, which points to high recent gene flow between Louvie and

Aubisque, which is in line with the absence of significant genetic differentiation among these populations and attribution to the same genetic cluster (Table 3; Fig. 2). The airline distance among these populations is less than $20 \mathrm{~km}$ and both populations are located in the same valley (Fig. 1). Given that $20 \mathrm{~km}$ is the shortest distance among sampled population pairs, the lack of differentiation is fully congruent with the detected IBD (Fig. 3).

The number of migrants per generation in population pairs including Louvie was generally high (average $=1.106 \pm 0.143 \mathrm{SE}$ ) and the majority of these population pairs exhibited more than one migrant per generation $(\mathrm{Nm}>1$; Table 3$)$. Moreover, only seven of the 45 comparisons (16\%) exhibited $\mathrm{Nm}>1$ and five of them were among

240 population pairs including Louvie (Louvie-Aubisque, Aubisque-Zuriza, Louvie-Zuriza, 241 Louvie-Pinet, Louvie-Beret, Louvie-Barazar, Estacas-Barazar; Table 3). In addition, 13 
of the 15 first-generation migrants detected in the dataset included Louvie. Seven individuals migrated from Louvie to Aubisque or Zuriza and six individuals migrated from Aubisque to Louvie. Louvie is located at the northern foothills of the Pyrenees (372 m asl; Fig. 1) and the population pairs including Louvie and exhibiting $N \mathrm{~m}>1$ were located in the North of the Pyrenees (Pinet) and in the North of the Cantabrian mountains (Barazar), in valleys with a northward-drainage system (Aubisque, Beret), or close to the central cordillera and a low altitude pass connecting the southern with the northern slope (Zuriza). This points to migration through the northern lowlands (e.g. from Louvie to Pinet, from Louvie along the coast to Barazar, or vice versa) and from the northern lowlands southwards through the valleys, or vice versa (e.g. from Louvie, to Beret, or to Zuriza, or vice versa). The high differentiation and low migration detected between populations whose airline distance crosses mountains suggests that longitudinal migration through the northern lowlands and latitudinal migration through the valleys are much easier than longitudinal migration through the mountains. This suggests that topography (i.e. mountain ranges) forms a physical barrier to migration, which agrees with conclusions by Milá et al. (2013). The results on Z.v. louislantzi contrast to those of Cornetti et al. (2015), which in the absence of physical barriers did not detect genetic exchange between clades $\mathrm{A}$ and $\mathrm{E}$ of $Z$. vivipara. Given that the common ancestor of clades $\mathrm{A}$ and $\mathrm{E}$ is much older than the common ancestor of subclades B2 and B4 (4.4 Mya versus 1.6 Mya; Horreo et al. 2018), the detected difference in reproductive isolation between the studies on Z.v. louislantzi and Cornetti et al.'s study (2015) suggests that the age of genetic differentiation among involved lineages might explain the observed differences. As commented above, migration was detected also among populations belonging to different subclades of Z.v. louislantzi (Fig. 1) and more specifically, among 
267 populations belonging to subclade B2 and B3, and populations belonging to subclade

268 B2 and B4 (Table 3). Migration among populations belonging to B2 and B4 is

269 congruent with the findings of Milá et al. (2013), who detected genetic introgression in

270 several populations (Fig. 6 in Milá et al. 2013), as for example between Gabas and

271 Turbera populations (Fig. 1B). This suggests that admixture among these subclades is

272 possible (see populations SOP and SOU; Fig. 6 in Milá et al. 2013). The split of

273 subclade B2 was estimated at 1.6 Mya (95\% CI: 1.2 - 2.0 Mya; Horreo et al. 2018) and

274 the split between subclade B1 and the other two subclades was estimated at 0.8 Mya

275 (0.5 - 1.2 Mya; Horreo et al. 2018), suggesting the existence of recent mixing among

276 relatively old subclades. The here detected strong genetic differentiation (Table 3; Fig.

277 2) also suggests that the observed gene flow was not sufficiently strong to balance the

278 genetic differences caused by past divergence.

279 It has been suggested that on the northern hemisphere climatic warming may

280 first affect populations at the southern range limit (Horreo et al. 2014) and at low

281 altitudes (Sinervo et al. 2010). The here detected low migration rates among populations

282 located south to the central Pyrenean cordillera (all belonging to subclade B4, the

283 southern limit of the natural distribution of Z. vivipara) might be in line with climate

284 warming that first disrupted connections through the lowlands South of the Pyrenees

285 and that may have let to the detected recent bottlenecks. Low migration rates among

286 populations belonging to the same subclade, together with strong genetic structuring,

287 significant heterozygote deficiency and the presence of recent bottlenecks point to

288 currently isolated populations (Allendorf et al. 2010; Bretman et al. 2011). B1 and B4

289 exhibited low migration rates among populations belonging to the same subclade (Table

290 3), significant heterozygote deficiency existed in all but one population (Table 2), and

291 evidence for recent bottlenecks existed in all populations of B1 and B2 and in some but 
not all populations of B3 and B4 (Table2), suggesting that most subclades might be threatened and thus the oviparous subspecies Z. v. louislantzi. On the other hand, the results also indicate that climatic warming may homogenise existing allele frequency differences thus removing genetic structure. Two first-generation migrants were detected in Zuriza, one coming from Louvie and the other one from Aubisque and there

297 existed gene flow between Zuriza and the other two populations ( $\mathrm{Nm}>1$, Table 3$)$. The detected migration together with the genetic introgression from Aubisque/Louvie detected in Zuriza (Fig. 2) indicates that recent gene flow may homogenise allele frequency differences thus removing genetic structures. This suggests that the fate of

301 populations located in the southern area of the Pyrenees (subclade B4) may depend on

302 whether or not gene flow with northern populations may become possible.

\section{Management implications}

Our results on the population structure of Z.v. louislantzi unravelled latitudinal

306 (north-southwards or vice versa) migration in the Pyrenees and longitudinal migration

307 through the lowlands north of the Pyrenees and the Cantabrian mountains, while in the

308 South of the central Pyrenean cordillera longitudinal (east-west) migration was very

309 weak and significant heterozygote deficiency existed. This suggests that topography

310 (mountains) forms a barrier to migration, that climatic conditions limit longitudinal

311 migration at the southern distribution limit, and that subclade B4 will be the first to be

312 affected by global warming. Management actions aiming at avoiding population

313 declines in Z.v. louislantzi (recent reductions in population sizes have been detected in

$31470 \%$ populations) might be required in all subclades, and start in populations belonging

315 to subclade B4. The strong population structure and the reduced migration among

316 different subclades also indicate that reintroductions and population reinforcements 
should be conducted with individuals belonging to the same subclade, in order to avoid

the loss of the existing allele frequency differences and potential negative effects on

319 population dynamics due to outbreeding depression.

\section{$320 \quad$ References}

Allendorf FW, Hohenlohe PA, Luikart G (2010) Genomics and the future of conservation genetics Nature Review Genetics 11:697-709

Aragon P, Fitze PS (2014) Geographical and temporal body size variation in a reptile: roles of sex, ecology, phylogeny and ecology structured in phylogeny PLOS ONE 9:e104026

Belkhir K, Borsa P, Chikhi L, Raufaste N, Bonhomme F (2004) GENETIX 4.05, logiciel sous Windows TM pour la génétique des populations. Laboratoire Génome, Populations, Interactions, CNRS UMR 5000, Université de Montpellier II, Montpellier

Bestion E, Clobert J, Cote J (2015) Dispersal response to climate change: scaling down to intraspecific variation Ecology Letters 18:1226-1233

Bretman A, Rodríguez-Muñoz R, Waklling C, Slate J, Tregenza T (2011) Fine-scale population structure, inbreeding risk and avoidance in a wild insect population Molecular ecology 20:3045-3055

Cornetti L, Belluardo F, Ghielmi S, Giovine G, Ficetola GF, Bertorelee G, Vernesi C, Hauffe HC (2015) Reproductive isolation between oviparous and viviparous lineages of the Eurasian common lizard Zootoca vivipara in a contact zone Biological Journal of the Linnean Society 114:566-573

Cote J, Clobert J, Fitze PS (2007) Mother-offspring competition promotes colonization success Proceedings of the National Academy of Sciences of the United States of America 104:9703-9708

Cotto O, Massot M, Ronce O, Clobert J (2015) Dispersal as a source of variation in agespecific reproductive strategies in a wild population of lizards Proceedings of the Royal Society B-Biological Sciences 282:20151741

Coulon A et al. (2004) Landscape connectivity influences gene flow in a roe deer population inhabiting a fragmented landscape: an individual-based approach Molecular ecology 13:2841-2850

Evanno G, Regnaut S, Goudet J (2005) Detecting the number of clusters of individuals using the software structure: a simulation study Molecular Ecology 14:26112620

Excoffier L, Lischer, HEL (2010) Arlequin suite ver 3.5: A new series of programs to perform population genetics analyses under Linux and Windows. Molecular Ecology Resources 10:564-567

Falush D, Stephens M, Pritchard JK (2007) Inference of population structure using multilocus genotype data: dominant markers and null alleles Molecular Ecology Notes 7:574-578

Fitze PS, Cote J, Clobert J (2010) Mating order-dependent female mate choice in the polygynandrous common lizard Lacerta vivipara Oecologia 162:331-341

Fitze PS, Le Galliard JF (2008) Operational sex ratio, sexual conflict and the intensity of sexual selection Ecology Letters 11:432-439

Garant D, Forde SE, Hendry AP (2007) The multifarious effects of dispersal and gene flow on contemporary adaptation Functional Ecology 21:434-443 
Garza J, Williamson E (2001) Detection of reduction in population size using data from microsatellite loci. Molecular ecology 10:305-318.

Geffen E, Anderson MJ, Wayne RK (2004) Climate and habitat barriers to dispersal in the highly mobile grey wolf Molecular ecology 13:2481-2490

Horreo JL, Fitze PS (2015) Population structure of three Psammodromus species in the Iberian Peninsula PeerJ 3:e994

Horreo JL, Machado-Schiaffino G, Griffiths AM, Bright D, Stevens JR, GarciaVazquez E (2014) Long-term effects of stock transfers: synergistic introgression of allochthonous genomes in salmonids Journal of Fish Biology 85:292-306

Horreo JL et al. (2018) Phylogeography, evolutionary history, and effects of glaciations in a species (Zootoca vivipara) inhabiting multiple biogeographic regions Journal of Biogeography in press

Horreo JL, Peláez ML, Suárez T, Heulin B, Fitze PS (2017) Development of thirty-four new microsatellite loci and multiplexing of seven existing loci for Zootoca vivipara Phyllomedusa 16:89-96

Horváthová T et al. (2013) Length of activity season drives geographic variation in body size of a widely distributed lizard Ecology and Evoluton 3:2424-2442

Kopelman NM, Mayzel J, Jakobsson M, Rosenberg NA, Mayrose I (2015) Clumpak: a program for identifying clustering modes and packaging population structure inferences across K Molecular Ecology Resources 15:1179-1191

Le Galliard JF, Fitze PS, Cote J, Massot M, Clobert J (2005) Female common lizards (Lacerta vivipara) do not adjust their sex-biased investment in relation to the adult sex ratio Journal of evolutionary biology 18:1455-1463

Li YL, Liu JX (2018) StructureSelector: A web based software to select and visualize the optimal number of clusters using multiple methods Molecular Ecology Resources 18:176-177

Merimans PG, Van Tienderen PH (2004) GENOTYPE and GENODIVE: two programs for the analysis of genetic diversity of asexual organisms Molecular Ecology Notes 4:792-794

Mila B, Surget-Groba Y, Heulin B, Gosá A, Fitze PS (2013) Multilocus phylogeography of the common lizard Zootoca vivipara at the Ibero-Pyrenean suture zone reveals lowland barriers and high-elevation introgression BMC Evolutionary Biology 13:192

Peñalver-Alcázar M, Aragon P, Breedvled MC, Fitze PS (2016) Microhabitat selection in the common lizard: implications of biotic interactions, age, sex, local processes and model transferability among populations Ecology and Evolution 6:3594-3607

Paetkau D, Slade R, Burden M, Estoup A (2004) Direct, real-time estimation of migration rate using assignment methods: a simulation-based exploration of accuracy and power. Molecular Ecology 13:55-65.

Piry S, Luikart G, Cornuet JM (1999) BOTTLENECK: a computer program for detecting recent reductions in the effective population size using allele frequency data Journal of Heredity 90:502-503

Piry S, Alapetite A, Cornuet, J-M, Paetkau D, Baudouin L, Estoup A (2004) GeneClass2: A Software for Genetic Assignment and First-Generation Migrant Detection. Journal of Heredity 95:536-539

Puechmaille SJ (2016) The program structure does not reliably recover the correct population structure when sampling is uneven: subsampling and new estimators alleviate the problem Molecular Ecology Resources 16:608-627 
Recknagel H, Kamenos N, Elmer KR (2018) Common lizards break Dollo's law of irreversibility: genome-wide phylogenomics support a single origin of viviparity and re-evolution of oviparity. Molecular Phylogenetics and Evolution 127:579-

415588.

Rannala B, Mountain JL (1997) Detecting immigration by using multilocus genotypes. Proceedings of the National Academy of Sciences USA 94:91979201

Rice WR (1989) Analyzing tables of statistical tests Evolution 43:223-225

San-Jose LM, Peñalver-Alcázar M, Milá B, Gonzalez-Jimena V, Fitze PS (2014) Cumulative frequency-dependent selective episodes allow for rapid morph cycles and rock-paper-scissors dynamics in species with overlapping generations Proceedings of the Royal Society B Biological Sciences 281:20140976

Sharma S, Dutta T, Maldonado JE, Wood TC, Panwar HS, Seidensticker J (2013) Forest corridors maintain historical gene flow in a tiger metapopulation in the highlands of central India Proceedings of the Royal Society B-Biological Sciences 280:20131506 doi:http://dx.doi.org/10.1098/rspb.2013.1506

Sinervo B et al. (2010) Erosion of lizard diversity by climate change and altered thermal niches Science 328:894-899

Slatkin M (1985) Rare alleles as indicators of gene flow. Evolution 39:53-65

Surget-Groba Y et al. (2006) Multiple origins of viviparity, or reversal from viviparity to oviparity? The European Common Lizard (Zootoca vivipara, Lacertidae) and the evolution of parity Biological Journal of the Linnean Society 87:1-11

Tobler M, Riesch R, Tobler CM, Schulz-Mirbach T, Plath M (2009) Natural and sexual selection against immigrants maintains differentiation among micro-allopatric populations Journal of evolutionary biology 22:2298-2304

Van Oosterhout C, hutchinson WF, Wills DPM, Shipley P (2004) MICRO-CHECKER: software for identifying and correcting genotyping errors in micrsaotellite data Molecular Ecology Notes 4:535-538

440 


\section{$442 \quad$ Figures}

444 Figure 1. Schematic maps showing the location of the sampled Zootoca vivipara lousilantzi populations. A) locations of the ten sampled Z. $v$. louizslantzi populations in northern Spain/southern France (dots). B) close-up of the Ossau and upper Tena Valley with drainage system. Dot

446 colour indicates subclade affiliation (yellow: B1, NW Spain; green: B2, S France; red: B3, NC Spain; blue: B4, NE Spain subclade). Thin arcs delimitate population pairs with significant gene flow $(N \mathrm{~m}>1)$, thick arcs with high gene flow $(N \mathrm{~m}>2)$, and the orange arc (panel B) reflects published evidence for gene flow (populations GAB: Gabas, TUR: Turbera; Mila et al. 2013). Map shading from white to dark brown indicates elevation above sea level, with dark brown representing highest elevation. The black line in the Pyrenees indicates the French-Spanish border, 

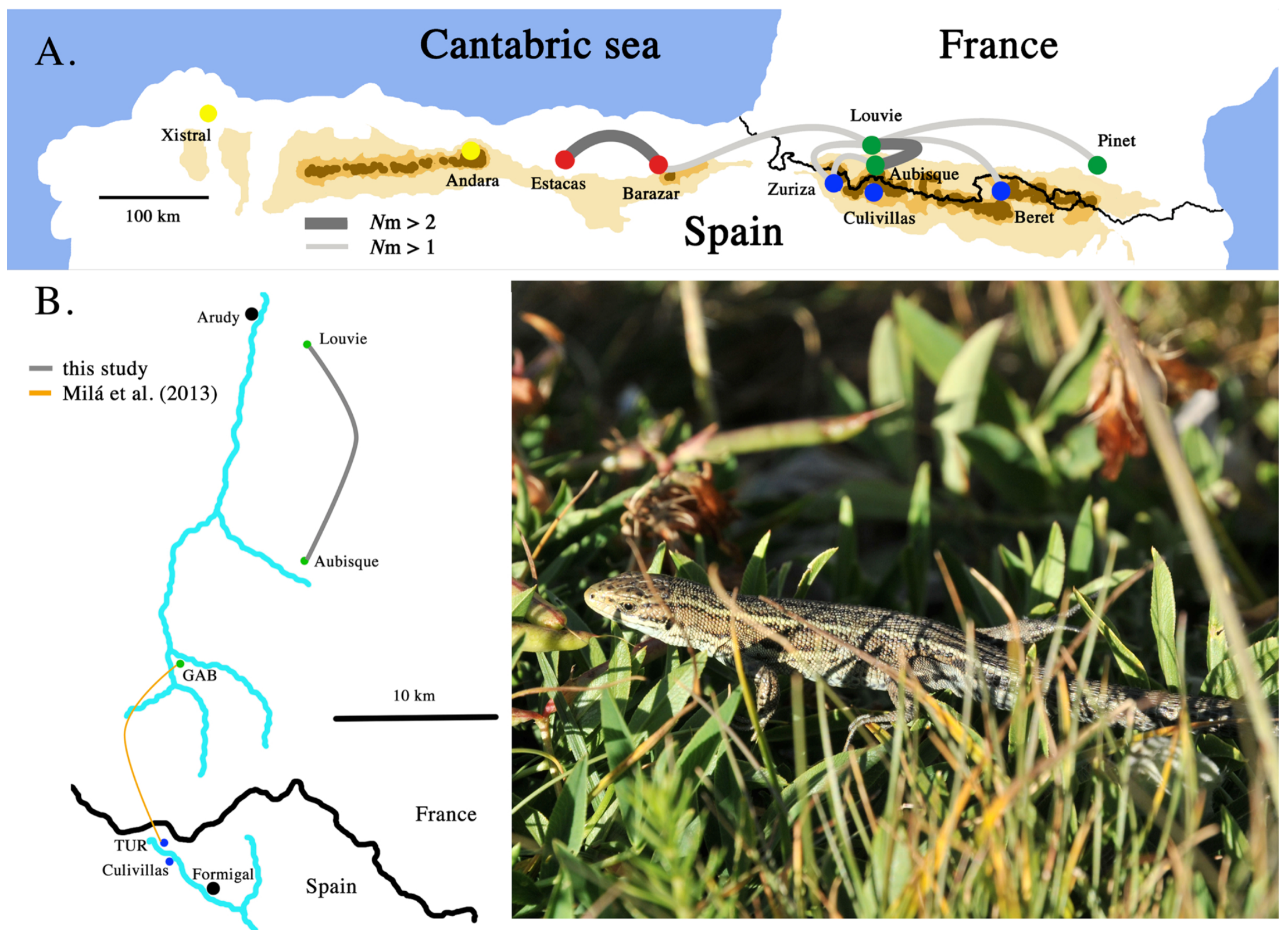
Fig. 2.- Structure output based on 28 microsatellite loci of the studied Z.v. louislantzi populations and an optimal number of genetic units of $K=$ 456 7. Each colour corresponds to a different cluster. Each vertical bar corresponds to the assignment probability to the genetic clusters of a single 457 individual.




louislanzi populations and the predicted regression line are plotted. The $P$-value of the regression line was $P<<0.01$.

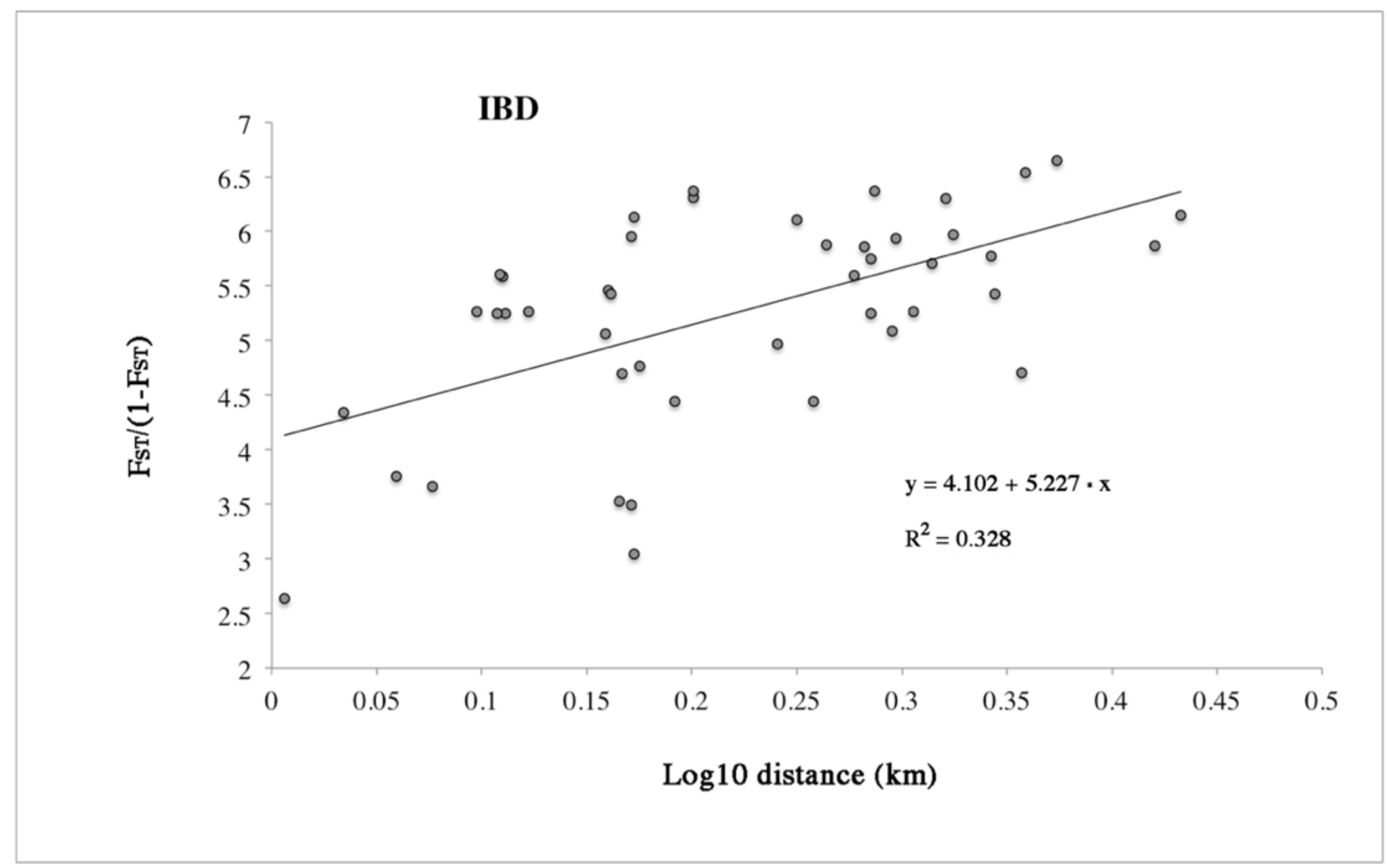


Table 1.- Genetic variability of the 34 microsatellites amplified in Z. v. louislantzi. Shown are the number of alleles per locus and population,

and the total number of alleles detected per locus (referred to as 'all'). '-' in Beret indicates that this locus did not amplify, and this value was not considered for the further analyses. Significant deviations from Hardy-Weinberg Equilibrium (HWE) are indicated with asterisk: $* P$-value $<$ 0.05 ; $* * P$-value $<0.01$. Three loci exhibited null alleles $(\mathrm{ZV} 17, \mathrm{ZV} 25$, and ZV33) and in another three loci $(\mathrm{ZV} 11, \mathrm{ZV} 12, \mathrm{ZV} 13)$ the majority of heterozygosities $(\mathrm{He})$, were calculated for the remaining 28 bold-faced loci.

\begin{tabular}{|c|c|c|c|c|c|c|c|c|c|c|c|}
\hline Subclade & \multicolumn{2}{|c|}{ B1 } & \multicolumn{3}{|c|}{ B2 } & \multicolumn{2}{|c|}{ B3 } & \multicolumn{3}{|c|}{ B4 } & \multirow[t]{2}{*}{ All } \\
\hline Locus/Pop & Andara & Xistral & Aubisque & Louvie & Pinet & Barazar & Estacas & Beret & Culivillas & Zuriza & \\
\hline ZV1 & 13 & 6 & 15 & 10 & 9 & 11 & 14 & 8 & 18 & 14 & 23 \\
\hline ZV2 & 2 & 13 & $12 *$ & 7 & $7 * *$ & $12 * *$ & $12 * *$ & 11 & $14 * *$ & 9 & 23 \\
\hline ZV3 & 9 & 9 & 15 & 12 & $6 * *$ & 10 & 10 & $6 * *$ & 9 & 9 & 23 \\
\hline ZV4 & 5 & 4 & 9 & 10 & 8 & 8 & 6 & 5 & 7 & 8 & 14 \\
\hline ZV5 & 8 & 7 & 12 & $13 * *$ & 7 & 8 & $12 * *$ & 9 & 10 & $10 *$ & 19 \\
\hline ZV6 & 8 & $8 * *$ & 15 & 13 & 10 & 7 & $8 * *$ & 9 & $7 * *$ & 12 & 20 \\
\hline ZV7 & 6 & 11 & 11 & 12 & 9 & 8 & 10 & 7 & 7 & 9 & 19 \\
\hline ZV8 & 8 & 5 & 10 & 14 & 10 & $12 * *$ & 11 & $9 *$ & 7 & $14 * *$ & 20 \\
\hline ZV9 & 7 & 5 & 12 & 11 & 8 & $10 * *$ & 8 & 7 & 7 & 13 & 20 \\
\hline ZV10 & 14 & 11 & 4 & 2 & 2 & 16 & 14 & - & 10 & 2 & 20 \\
\hline ZV11 & $13 * *$ & $10 * *$ & $12 *$ & $11^{*}$ & 13 & $12 * *$ & $13 * *$ & 10 & $10 * *$ & $11 * *$ & 21 \\
\hline ZV12 & 2 & 4 & $10 *$ & $15 * *$ & $7 * *$ & $9 * *$ & $8 * *$ & $5 * *$ & $4 * *$ & $10 * *$ & 18 \\
\hline
\end{tabular}




\begin{tabular}{|c|c|c|c|c|c|c|c|c|c|c|c|}
\hline ZV13 & 5 & 5 & $7 * *$ & $17 * *$ & $12 * *$ & $8 * *$ & $7 * *$ & 5 & 6 & $9 * *$ & 23 \\
\hline ZV14 & 8 & 7* & $12 * *$ & 12 & $9 *$ & 12 & $12 * *$ & 3 & 2 & 7 & 24 \\
\hline ZV15 & 6 & 12 & $15^{*}$ & 14 & $12 * *$ & 13 & 12 & 13 & 14 & 15 & 26 \\
\hline ZV16 & 9 & 8 & 9 & $8 * *$ & 6 & 9 & 10 & 8 & 11 & 10 & 17 \\
\hline ZV17 & 9 & 7 & $15^{*}$ & $8 * *$ & $14 * *$ & 12 & $9 *$ & $13 * *$ & 9* & 10 & 21 \\
\hline ZV18 & 2 & 3 & $11^{* *}$ & 6 & 11 & $10 * *$ & 11 & $13^{*}$ & 8 & $10^{*}$ & 19 \\
\hline ZV19 & 7 & 10 & 13 & 11 & 4 & $9 *$ & 11 & 8 & 8 & 9 & 20 \\
\hline ZV20 & 10 & 10 & 9 & 12 & 12 & 13 & 15 & 5 & $10^{*}$ & 10 & 22 \\
\hline ZV21 & 11 & 10 & 12 & 9 & 11 & 14 & 12 & 7 & 9 & $5^{*}$ & 18 \\
\hline ZV22 & $5 * *$ & 7 & 13 & 14 & 14 & 10 & 10 & 8 & $5 * *$ & 7 & 21 \\
\hline ZV23 & 8 & 3 & 15 & 15 & 12 & 10 & $8^{*}$ & 9 & 9 & $9^{*}$ & 20 \\
\hline ZV24 & $5^{* *}$ & 3 & 12 & 11 & 7 & 9 & 8 & 6 & 4 & $10^{*}$ & 16 \\
\hline ZV25 & 10 & $8 * *$ & 9 & 12 & 7 & $11 * *$ & $10 * *$ & 8 & 7 & 7 & 15 \\
\hline ZV26 & 5 & 9 & 15 & 16 & 9 & 12 & 18 & 6 & 9 & $11 *$ & 24 \\
\hline ZV27 & 10 & 2 & 8 & 8 & 14 & $8 * *$ & 13 & 8 & 6 & $9^{*}$ & 24 \\
\hline ZV28 & 10 & 10 & $8 * *$ & $10^{* *}$ & 8 & 12 & $12^{*}$ & 5 & 8 & $9 * *$ & 20 \\
\hline ZV29 & 3 & 2 & $7 * *$ & 9 & 2 & 6 & $6^{* *}$ & 4 & 7 & 9 & 15 \\
\hline ZV30 & $7 *$ & 17 & 14 & 14 & 10 & 11 & 12 & 9 & 9 & $13^{*}$ & 24 \\
\hline ZV31 & 6 & 12 & $17 *$ & 14 & $9 * *$ & 10 & $9 * *$ & 11 & $15^{* *}$ & $12 * *$ & 21 \\
\hline ZV32 & 11 & 10 & $15^{* *}$ & 16 & 11 & 7 & 10 & 10 & 11 & 12 & 25 \\
\hline ZV33 & 4 & 7 & 11 & 9 & 7 & 6 & 6 & 6 & 6 & 10 & 12 \\
\hline ZV34 & 3 & 3 & 18 & $17 *$ & 9 & 9 & $7 * *$ & 14 & $9 * *$ & 9 & 27 \\
\hline Average Na & 7.36 & 7.75 & 12.07 & 11.43 & 8.78 & 10.21 & 10.75 & 8.07 & 8.93 & 9.86 & 20.86 \\
\hline Ho & 0.60 & 0.60 & 0.70 & 0.70 & 0.62 & 0.68 & 0.70 & 0.60 & 0.62 & 0.64 & - \\
\hline $\mathrm{He}$ & 0.60 & 0.60 & 0.82 & 0.81 & 0.71 & 0.76 & 0.78 & 0.63 & 0.65 & 0.75 & - \\
\hline
\end{tabular}


Table 2.- Heterozygote deficiency ( $\mathrm{F}_{\mathrm{s}} ; *$ indicates $P<0.05$ after Bonferroni correction for multiple tests), $P$-values of Wilcoxon tests, and

476 Garza-Williamson $(\mathrm{G}-\mathrm{W})$ index for the studied Z.v. louislantzi populations. Significant Wilcoxon tests indicate recent bottlenecks, while G-W <

4770.68 points to presence, and G-W $>0.8$ to absence of past bottlenecks. Subclade corresponds to the subclade affiliation and the distribution range

478 following Horreo et al. (2018) and Milá et al (2013). GPS coordinates are shown in Latitude (Lat) and Longitude (Long).

\begin{tabular}{|c|c|c|c|c|c|c|}
\hline Population & Subclade/distribution & Lat & Long & $\mathbf{F}_{\text {is }}$ & Wilcoxon & G-W \\
\hline Andara & B1: NW Spain & $43^{\circ} 13^{\prime} 2.62^{\prime \prime} \mathrm{N}$ & $4^{\circ} 42^{\prime} 57.37^{\prime \prime} \mathrm{W}$ & $0.002^{*}$ & 0.009 & 0.841 \\
\hline Xistral & B1: NW Spain & $43^{\circ} 28^{\prime} 0.41^{\prime \prime} \mathrm{N}$ & $7^{\circ} 32^{\prime} 14.14^{\prime \prime} \mathrm{W}$ & -0.004 & 0.000 & 0.954 \\
\hline Aubisque & B2: S France & $42^{\circ} 58^{\prime} 17.87^{\prime} \mathrm{N}$ & $0^{\circ} 20^{\prime} 43.19$ ' W & $0.146^{*}$ & 0.015 & 0.952 \\
\hline Louvie & B2: S France & $43^{\circ} 5^{\prime} 40.19^{\prime \prime} \mathrm{N}$ & $0^{\circ} 22^{\prime} 52.52^{\prime \prime} \mathrm{W}$ & $0.135^{*}$ & 0.022 & 0.969 \\
\hline Pinet & B2: S France & $42^{\circ} 51^{\prime} 38.22^{\prime} \mathrm{N}$ & 1'58'44.62’'E & $0.128 *$ & 0.005 & 0.955 \\
\hline Barazar & B3: NC Spain & $43^{\circ} 3^{\prime} 32.47^{\prime \prime} \mathrm{N}$ & $2^{\circ} 43^{\prime} 7.65^{\prime \prime} \mathrm{W}$ & $0.111^{*}$ & 0.063 & 0.929 \\
\hline Estacas & B3: NC Spain & $43^{\circ} 7^{\prime} 2.02^{\prime \prime} \mathrm{N}$ & $3^{\circ} 42^{\prime} 3.56^{\prime \prime} \mathrm{W}$ & $0.103 *$ & 0.028 & 0.913 \\
\hline Beret & B4: NE Spain & $42^{\circ} 42^{\prime} 57.58^{\prime \prime} \mathrm{N}$ & 057'16.97’'E & $0.053^{*}$ & 0.141 & 0.931 \\
\hline Culivillas & B4: NE Spain & $42^{\circ} 47^{\prime} 8.61^{\prime \prime} \mathrm{N}$ & $0^{\circ} 23^{\prime} 51.50^{\prime \prime} \mathrm{W}$ & $0.046^{*}$ & 0.104 & 0.872 \\
\hline Zuriza & B4: NE Spain & $42^{\circ} 51^{\prime} 31.59 \mathrm{~N}$ & $0^{\circ} 47^{\prime} 55.87^{\prime \prime} \mathrm{W}$ & $0.144^{*}$ & 0.011 & 0.934 \\
\hline
\end{tabular}




\begin{tabular}{|c|c|c|c|c|c|c|c|c|c|c|c|}
\hline \multirow[t]{2}{*}{\begin{tabular}{|l} 
Subclade \\
\end{tabular}} & \multirow[b]{2}{*}{ Population } & \multicolumn{2}{|c|}{ B1 } & \multicolumn{3}{|c|}{ B2 } & \multicolumn{2}{|c|}{ B3 } & \multicolumn{3}{|c|}{ B4 } \\
\hline & & Andara & Xistral & Aubisque & Louvie & Pinet & Barazar & Estacas & Beret & Culivillas & Zuriza \\
\hline \multirow[b]{2}{*}{ B1 } & Andara & - & 0.403 & 0.607 & 0.641 & 0.409 & 0.456 & 0.575 & 0.349 & 0.323 & 0.422 \\
\hline & Xistral & $0.256^{*}$ & - & 0.789 & 0.948 & 0.485 & 0.359 & 0.527 & 0.361 & 0.528 & 0.579 \\
\hline \multirow[b]{3}{*}{ B2 } & Aubisque & $0.209 *$ & $0.167 *$ & - & 2.149 & 0.993 & 0.952 & 0.867 & 0.918 & 0.781 & 1.059 \\
\hline & Louvie & $0.220^{*}$ & $0.167 *$ & 0.006 & - & 1.025 & 1.038 & 0.971 & 1.028 & 0.851 & 1.303 \\
\hline & Pinet & $0.243^{*}$ & $0.272 *$ & 0.097* & $0.109 *$ & - & 0.593 & 0.598 & 0.901 & 0.447 & 0.722 \\
\hline \multirow[b]{2}{*}{ B3 } & Barazar & $0.228^{*}$ & $0.245^{*}$ & $0.089 *$ & $0.100^{*}$ & $0.146^{*}$ & - & 2.039 & 0.479 & 0.382 & 0.721 \\
\hline & Estacas & $0.205^{*}$ & $0.222 *$ & $0.098^{*}$ & $0.099 *$ & $0.147 *$ & $0.033^{*}$ & - & 0.488 & 0.409 & 0.652 \\
\hline \multirow[b]{3}{*}{ B4 } & Beret & $0.302^{*}$ & $0.264^{*}$ & $0.143^{*}$ & $0.149^{*}$ & $0.161^{*}$ & $0.239 *$ & $0.229^{*}$ & $1-$ & 0.325 & 0.627 \\
\hline & Culivillas & $0.296^{*}$ & $0.223^{*}$ & $0.147 *$ & $0.142 *$ & $0.234^{*}$ & $0.222 *$ & $0.217 *$ & $0.263^{*}$ & - & 0.708 \\
\hline & Zuriza & $0.255^{*}$ & $0.200^{*}$ & $0.071^{*}$ & $0.056^{*}$ & 0.139* & 0.137 * & $0.138^{*}$ & $0.194 *$ & $0.146^{*}$ & - \\
\hline
\end{tabular}


